\title{
Self-Esteem, Self-Efficacy, and the Balance of Peer Support Among Persons With Chronic Mental Health Problems
}

\author{
Piet Bracke, ${ }^{1}$ Wendy Christiaens, and Mieke Verhaeghe \\ Department of Sociology \\ Ghent University \\ Ghent, Belgium
}

\begin{abstract}
Despite several suggestions that peer support is empowering for persons with mental health problems because of its mutual nature, few studies have empirically studied the role of its reciprocity and the effects on subjective well-being of clients from mainstream mental health care settings. Using data of 628 users of vocational and psychiatric rehabilitation centers $(N=51)$ in Flanders, the effects of the reciprocity of peer support on self-esteem and self-efficacy are explored by testing hypotheses derived from the theories of exchange, social capital, equity, and self-esteem enhancement. Results show that providing peer support is more beneficial than receiving it. One conclusion is that the net beneficial effects of receiving support from peers are overestimated.
\end{abstract}

The beneficial effects of social support are generally accepted (Cohen \& Wills, 1985; Kessler, Price, \& Wortman, 1985; Lin \& Peek, 1999; Thoits, 1995; Turner \& Turner, 1999). Nevertheless, several studies have suggested that receiving support is not always helpful. For instance, when it elicits feelings of dependence, failure, and powerlessness in the support receiver, it is often associated with increased distress (for a review, see Barrera, 1986).

Other research has shown that the benefits of social support are sometimes associated with giving instead of receiving support (Brown, Nesse, Vinokur, \& Smith, 2003; Roberts et al., 1999). Helping others increases helpers' feelings of competence and social usefulness (Riessman, 1965; Skovholt, 1974) and makes them feel important to someone else (Taylor \& Turner, 2001).

Finally, providing support can be harmful, too. Caring for someone can wear the caregiver out and can lead to negative emotions, such as feeling used or frustrated. Together, these findings suggest that beneficial support relationships consist of a healthy mix of receiving and providing support.

In the realm of mental health services working from a rehabilitation perspective (Anthony, Cohen, \& Farkas, 1990; Pickett, Cook, \& Razzano,

${ }^{1}$ Correspondence concerning this article should be addressed to Piet Bracke, Department of Sociology, Ghent University, Korte Meer 5, B-9000 Ghent, Belgium. E-mail: Piet.Bracke@, UGent.be

Journal of Applied Social Psychology, 2008, 38, 2, pp. 436-459.

(C) 2008 Copyright the Authors

Journal compilation (C) 2008 Blackwell Publishing, Inc. 
1999; Wilken \& den Hollander, 1999), the notion that balanced support has ameliorating effects comes as no surprise. The development of peer-support networks among people with chronic mental illness is explicitly encouraged in order to enlarge their networks and to diminish their dependence on professionals. Peer contacts are seen as complementary to - or sometimes as opposed to - contacts with professionals because, in contrast to the latter, the former are characterised by equality and mutuality, allowing for both receiving and giving social support. For instance, professional barriers discourage therapists from sharing their problems with their clients, preventing the development of balanced support relations between them (Wilson, Flanagan, \& Rynders, 1999). Hence, various initiatives (e.g., mutual support groups, consumer-run services, use of consumers as providers) are strongly encouraged (Davidson et al., 1999; Solomon, 2004).

Nevertheless, research on the balance between providing and receiving support in peer-support networks of clients of mental health services is very rare. Up to now, those studying reciprocity in social support have neglected peer support among clients of mental health services, while those concentrating on peer support among consumers of mental health services have not systematically investigated the balance between providing and receiving support, or have limited their research to self-help or mutual-help groups or specialized peer-support services.

As a result, the consequences of the balance of support among naturally occurring peer-support groups among persons with chronic mental health problems in formal mental health care settings have not been systematically investigated. The present study attempts to fill this gap using information provided by a multistage sample of clients $(N=628)$ of rehabilitation centers $(n=51)$ providing day activities for people with chronic mental health problems in Flanders (Belgium). Using information on the amount of peer support received and provided, the effects of the balance of peer support on two dimensions of the subjective well-being of the clients - their self-esteem and their self-efficacy - are estimated. Furthermore, using multilevel analysis, some organizational and individual determinants of the balance of peer support are explored.

\section{Balance of Support}

Before proceeding to discuss the effects of the receipt and provision of support on subjective well-being, it is important to point to the importance of the distinction between the balance of support and the reciprocity of support (Jung, 1997). As Jung stated, the concepts are similar in that they both deal with the ratio between provision and receipt of support. Nevertheless, while 
the latter signifies exchanges over time between the same individuals, the former denotes the equivalence of total received and provided support across all network members.

In peer-support groups, the balance of support is more relevant because support exchange is seldom dyadic, but more often takes the form of generalized exchange (Ekeh, 1974; Takahashi, 2000; Yamagishi \& Cook, 1993). In generalized exchange, there is no one-to-one correspondence between what two actors directly give and receive from each other: The person someone relies on for support is not always the one who is given support. Usually, we support someone and are supported by someone else. Williams (1995) pointed to the importance of stepwise reciprocity in social support networks to denote the same phenomenon. So, even if dyadic relationships lack reciprocity, generalized exchange can lead to an overall balance of support in peer-support groups. Hence, for the link between peer support and subjective well-being, the balance of support is probably more relevant.

\section{Benefits and Costs of Receiving and Providing Support}

The beneficial effects of social support are generally accepted (Cohen \& Wills, 1985; Kessler et al., 1985; Lin \& Peek, 1999; Thoits, 1995; Turner \& Turner, 1999). For people with chronic mental health problems, peer support means a network of people with similar experiences to whom they can turn for support and assistance. Peer-support groups, furthermore, offer a sense of belonging and positive feedback of a person's self-worth (Solomon, 2004).

Nevertheless, there are limits to the healing potential of receiving support from others. Receiving support can be associated with increased distress and has the potential to be a threat to self-esteem when it elicits feelings such as dependence, inferiority, failure, and powerlessness (Barrera, 1986; Fisher, Nadler, \& Whitcher-Alagna, 1982; Roberts et al., 1999). In the realm of mental health services, these detrimental effects are usually associated with therapist-client relationships, but there is no reason to assume that peer support is unaffected by these negative consequences.

Providing support can help to mitigate the negative effects of support receipt. According to the helper-therapy principle (Riessman, 1965; Skovholt, 1974), helping others increases the helper's feelings of competence and social worth. The helper feels an enhanced sense of self-efficacy from having an impact on another's life and acquires an enhanced sense of self from the social approval received for those helped. This principle is similar to the mattering principle (Taylor \& Turner, 2001), which implies that the experience of being important for someone else is beneficial. Both features are readily recognized in peer-support groups (Solomon, 2004) or in self-help 
or mutual-help groups (e.g., Roberts et al., 1999; Salem, Reischl, Gallacher, \& Randall, 2000).

However, even the healing power of providing support seems to have its limits. The concepts of caregiver burden, carer distress, or cost of caring (England \& Folbre, 1999; Hunt, 2003; Pearlin, Mullan, Semple, \& Skaff, 1990) neatly summarize the observation that caring for someone can wear out the caregiver and can lead to negative emotions, such as feeling used or frustrated. Again, peer-support networks of individuals with severe mental illness are not immune to the harmful effects of providing support. First, the support providers themselves are in need of support for the problems they face, rendering them especially vulnerable to caregivers' role overload. Second, peer-support networks are often characterized by interpersonal conflicts (Goering et al., 1992), while at the same time, their members have more difficulty trying to solve them.

In sum, receiving and providing support are beneficial, up to a certain limit. This implies that effective peer-support groups are characterized by a certain balance of support or by an optimal combination of both receiving and providing support. The question is what constitutes an optimal balance of support? Does the optimum fall on the side of receiving support, on the side of providing support, or more or less in between? The answer probably depends on the outcome measure used. What is the most optimal balance of support in terms of enhancing feelings of self-esteem or feelings of self-efficacy?

\section{Self-Esteem, Self-Efficacy, and the Optimal Balance of Support}

Starting from the literature, three hypotheses concerning the optimal balance of support can be derived. The first hypothesis is linked to equity theory (Walster, Walster, \& Berscheid, 1978), the norm of reciprocity (Gouldner, 1960; Uehara, 1995), and the bidirectional hypothesis (Maton, 1987; Roberts et al., 1999). According to equity theory (Walster et al., 1978), those in an equitable relationship are more content (Liang, Krause, \& Bennett, 2001). Being able to both give and take, in equal amounts, allows individuals to avoid the costs of both overbenefiting and underbenefiting from a support relation.

Those who are overbenefiting are distressed and feel guilty because receiving more support than they have provided violates the norm of reciprocity and may lead to a state of dependence (Liang et al., 2001). Those who are underbenefiting experience negative feelings, too, because they feel as if others are taking advantage of them, and they become irritated. In contrast, those in a situation of balanced support are able to enjoy the virtues of receiving support knowing that they are able to reciprocate by providing 
support in the future and vice-versa, in accordance with the norm of reciprocity (Gouldner, 1960).

The bidirectional support hypothesis (Maton, 1987) states that there are costs for receiving help from others and costs for providing help to others. So, over time, group members involved in balanced, flexible patterns of providing and receiving support will experience fewer psychological costs of receiving and providing support than will individuals who primarily receive or primarily provide support. They can accumulate the benefits of both providing and receiving and avoid the mental health costs of unidirectionally receiving or unidirectionally providing support (Maton, 1988).

The second hypothesis is linked to the more conventional social support hypothesis and stresses that the positive effects of receiving support largely exceed the negative effects. Receiving support generates rewards, such as a sense of belonging, feelings of self-esteem, or feelings of self-worth (Sarason, Pierce, \& Sarason, 1994). From an exchange perspective, benefits derive from reward maximization: Overbenefiting should lead to less distress, while underbenefiting would make one more distressed (Liang et al., 2001).

The last hypothesis is related to social capital theory (Bourdieu, 1984; Coleman, 1990) and self-esteem enhancement theory (Batson, 1998). Social capital theory recently has been linked more systematically to the social support literature (Macinko \& Starfield, 2001; Rose, 2000), assuming that social capital or an individual's informal and formal links with others are a social support resource or a support debt (Antonucci \& Jackson, 1990) that can be called on in the future when needed. This social capital can wear out if it is used without replenishing. So, it is better that the provision of support exceeds the receipt of support.

Finally, self-esteem enhancement theory (Batson, 1998) states that providing support to someone in need-underbenefiting - leads to esteem enhancement, hence increased well-being. On the other hand, overbenefiting or receiving support leads to a more negative self-evaluation. One acknowledges a lack of competence, a lack of knowledge, or a lack of other resources to cope, which damages one's self-esteem. As a result, people try to avoid overbenefiting (Uehara, 1995) by being reluctant to accept help when needed or by creating a support debt. Both hypotheses predict better outcomes for individuals with a positive support-provision/support-receipt balance.

These hypotheses clearly predict the effects on the balance of support for various combinations of support provision and support receipt. Less clear are the differential effects of the balance of support on self-esteem and self-efficacy. Most authors acknowledge the effects of the balance of support on both components of the self (Antonucci \& Jackson, 1990; Coyne, Ellard, \& Smith, 1990; Liang et al., 2001; Schwartz \& Sendor, 1999; Skovholt, 1974), but few have tried to disentangle the paths leading from the receipt and 
provision of support to both components of well-being. Nevertheless, starting from the social roots of both dimensions of the self-concept, some hypotheses can be easily derived.

Self-esteem and self-efficacy are two interrelated dimensions of selfconcept formation (Gecas, 1982; Thoits \& Hewitt, 2001). While the first is based on a sense of social worth generated via processes of reflected appraisals, the latter is based more on a sense of competence, power, and control related to effective performance (Bandura, 1997). Self-efficacy refers to people's assessment of their effectiveness, competence, and causal agency (Gecas, 1989). Because receiving and providing support denote different meanings for the social competence and the social worth of an individual, the balance of support probably has different consequences for self-esteem and self-efficacy.

Being able to provide support signals social competence and problemsolving capacities. Furthermore, it augments support debt and social capital and hints at the availability of social support as a future coping resource. Hence, in terms of self-efficacy, an excess of giving over receiving probably characterizes an optimal balance of support.

Effects of the balance of support on self-esteem are more complicated. Because self-efficacy is one of the precursors to self-esteem (Gecas, 1982), social processes that augment self-efficacy also enhance self-esteem. Besides these indirect effects on self-esteem, some additional, direct effects of receiving support on self-esteem are possible. Receiving support in general (Sarason et al., 1994; Thoits, 1995) - and peer support, more specifically (Solomon, 2004) - offers a sense of belonging; the perception of being loved, valued, and cared for by others; and positive feedback of a person's own self-worth. Hence, in terms of self-esteem, an optimal balance of support probably results from a combination of direct effects and indirect effects via self-efficacy, and possibly holds the middle between balanced support and excess support provision.

\section{Past Research}

There is scant evidence regarding the appropriateness of these hypotheses. For instance, Thoits and Hewitt (2001) reported that, in volunteer work, giving support is related to self-esteem and self-efficacy, but the effects on self-efficacy are more pronounced. Liang et al. (2001) found evidence that providing support enhanced self-esteem in a national sample of individuals aged 65 or older. Schwartz and Sendor (1999) reported increased selfconfidence in peer telephone supporters as a result of giving support. Roberts et al. (1999) found that in mutual-help groups for individuals with serious mental illness, providing help increased the helpers' feelings of competence and social usefulness. 
In a peer-support program for persons with recurrent mental health and substance abuse disorders, Salzer and Shear (2002) indicated that 14 peersupport specialists reported feeling appreciated, feeling important, enhanced self-esteem, and enhanced confidence as perceived benefits of helping. Armstrong and Korba (1995) provided anecdotal information of positive changes in self-perception, sense of identity, and personal development among consumer volunteers for people with psychiatric disabilities, and the importance of the reciprocity of their relationships with the clients. Support providers in client-run self-help agencies for persons with severe mental disabilities have shown enhanced self-esteem and self-efficacy (Segal, Silverman, \& Temkin, 1995).

For several reasons, the findings of most empirical studies on the effects of the balance of support or support reciprocity on well-being do not provide a direct test of the aforementioned hypotheses for persons with chronic mental health problems. Some studies are confined to small samples or to specific subgroups of the general, non-treated population (Ingersoll-Dayton \& Antonucci, 1988; Israel \& Antonucci, 1987; Jung, 1990, 1997; Liang et al., 2001; Lu, 1997; Lu \& Argyle, 1992; Maton, 1987; Schwartz, Meisenhelder, Ma, \& Reed, 2003). These studies show that providing support or support reciprocity is preferred. The problem is that, compared to persons with serious mental health problems, members of the general population have less need for support and are probably more able to provide various forms of support.

Others studies have concentrated on members of mutual-help and self-help groups (Hogan, Linden, \& Najarian, 2002). In most of these investigations, the beneficial effects of peer support are assumed to result from the opportunity both to give and to receive support from similar others. Only a few studies explicitly measure the amount of support provided and received (Maton, 1988; Roberts et al., 1999). They confirm the beneficial effects of providing support or support reciprocity. Nevertheless, only one study (Roberts et al., 1999) focused on persons with chronic mental health problems.

One line of research on the effects of peer support in more formal care settings is confined to the position of peer-support specialists and to consumer-run services (Davidson et al., 1999). The former have shown the beneficial effects of helping among peer-support specialists (Armstrong \& Korba, 1995; Mowbray \& Moxley, 1998; Salzer \& Shear, 2002; Schwartz \& Sendor, 1999). Again, mutuality of support is assumed to be a defining characteristic of these services and seldom has been investigated empirically. Furthermore, findings from these innovative approaches probably cannot be generalized to naturally occurring peer-support relations. Relationships between peer-support specialists and regular clients of mental health services are more or less guided by conventional definitions of therapeutic boundaries 
(Davidson et al., 1999) and thus fall in between natural peer-support relationships and therapeutic relationships.

Finally, another line of research on peer support in formal settings concentrates on social-support interventions led by professionals (Hogan et al., 2002). These studies suggest that systems that encourage support reciprocity may be especially helpful, but none of them actually measure giving and receiving peer support. Furthermore, the results of these studies are limited in that members of these initiatives are only a small fraction of all consumers of mental health services and very often are not representative of the overall client population.

In sum, the present study concentrates on the effects of the balance between providing and receiving support in the peer groups of clients of day-activity programs of rehabilitation centers for persons with chronic mental health problems. We focus on two important dimensions of subjective well-being - self-esteem and self-efficacy - and study the relationship between subjective well-being and the balance of peer support in the egocentered networks of persons in naturally occurring peer-support groups.

\section{Method}

\section{Sample}

Data were collected in rehabilitation centers providing day-activity programs for people with chronic mental health problems in Flanders (Belgium). Data collection took place from February through July 2002. The survey covers most of the day-activity centers connected to the Flemish psychosocial rehabilitation centers (the population consists of seven organizations providing services at nine different locations), and a random sample of day-activity programs associated with Flemish vocational rehabilitation centers and social service organizations (the population consists of 90 organizations).

The survey gathered data at the level of clients, staff, and organizations. In each participating service organization, researchers interviewed all personnel. They asked random samples of clients to participate. The number of respondents per organization was a function of the daily average number of clients, with a maximum of 30 participants per organization. Two research assistants visited each facility, using structured questionnaires to interview each client personally.

The data contain information on 628 clients ( 396 male, 232 female) of 51 service organizations. We excluded 38 clients for a lack of information on key variables. Of the remaining clients, $63 \%$ were men, $26.3 \%$ earned a primary degree, $61 \%$ finished high school, and $11 \%$ finished higher education. 


\section{BRACKE ET AL.}

Participants' mean age was 44 years. The majority (54\%) were single, 20\% were married, $22 \%$ were divorced, and $3 \%$ were widowed. Most $(32 \%)$ of the respondents lived in supported housing, 24\% lived alone, 20\% lived with a partner, $16 \%$ lived with their parents, and the remaining $8 \%$ lived with their children or with other family members. Finally, $78 \%$ of the participants had received residential psychiatric care.

\section{Dependent Variables}

Self-esteem. Self-esteem was measured using a Flemish version (Brutsaert, 1993; Bruynooghe, Bracke, \& Verhaeghe, 2003) of Rosenberg's (1965) global self-esteem scale. This inventory consists of 10 items focusing on overall self-evaluations, such as perceptions of self-worth, usefulness, and failure. The scale is internally consistent $(\alpha=.85)$ and has satisfying psychometric properties (Bruynooghe et al., 2003). Using the same scale, Rosenfield and Wenzel (1997) reported an alpha of .82 in a sample of adults with chronic mental problems associated with a community mental health center. Arns and Linney (1993) reported an internal consistency of the same magnitude in a sample of people from psychosocial rehabilitation programs.

Self-efficacy. Self-efficacy refers to people's assessment of their effectiveness, competence, and causal agency (Gecas, 1989). In the present study, the construct is measured using an abbreviated, 12-item Dutch version (Bosscher \& Smit, 1998) of Sherer et al.'s (1982) self-efficacy scale, which measures people's general sense of personal efficacy or mastery. Internal consistency of the scale is good $(\alpha=.80)$. Corrected item-total correlations ranged between .29 and .55 .

\section{Independent Variables}

To measure the balance of support or to measure support reciprocity, single-item questions are used most often (Jung, 1990). Moreover, some studies stimulate socially desirable answering or the overreporting of support reciprocity by relying on direct measures; that is, indicators asking respondents to report support relations characterized by reciprocity (Jung, 1990).

Following others (Jung, 1997; Nelson, Hall, Squire, \& Walsh-Bowers, 1992), we inferred the balance of support in the peer-support networks of clients by comparing the scores of two measures of social support: an indicator of support received from peers, and an indicator of support provided to peers. Each indicator is a four-item, Likert-type indicator of supportive transactions. To measure support provided, respondents were asked to 
indicate how many times (a) "Someone (i.e., the client) asks your help for a job/household chores"; (b) "Someone stops by for a cozy/warm conversation"; (c) "Someone contacts you to talk about his/her problems"; and (d) "Someone comes to you because she/he has $100 \%$ confidence in you." Responses were rated on a 5-point scale ranging from 1 (never) to 5 (a lot). The wording was adapted to measure the amount of support received. Taking into account their brevity, both indicators show good reliability. Cronbach's alphas were .72 and .69 for support provided and support received, respectively, which is comparable to the reliabilities found by Nelson et al. (1992) for similar scales.

The total amount of balanced peer support was determined by averaging the scores on the indicator of support provided and the indicator of support received. This indicator measures the overall supportive nature of the peer network of the clients $(M=2.56, S D=0.76)$.

The inequity of peer support was measured as the amount of support provided to peers minus the amount of support received from peers $(M=0.30, S D=0.79)$. Note that this indicator measures the imbalance in the total amount of support provided and received over the entire ego-centered network, and not the amount of asymmetrical dyadic support relations. In other words, it takes into account the inequity in the amount of generalized support exchange in peer-support groups. This strategy is similar to the one used by Ingersoll-Dayton and Antonucci (1988).

Using both the average of and the difference between support provided and support received allows us to separate the effects of the mean amount of perceived support from the perceived support inequity in a given peersupport network. Entering both indicators in the same model is necessary because unbalanced and balanced support are possible both at low and high levels of total support, and both conditions should not be equated.

\section{Client-Level Control Variables}

Previous contact with psychiatric inpatient services measures contact with psychiatric residential care during the 12 months preceding participation in the rehabilitation program. Scores were rated on the following scale: $0=n o$ contact with residential psychiatric care; $1=$ admission to either a general psychiatric hospital or a psychiatric ward in a general hospital; and $2=$ admission to both types of residential psychiatric care. While neglecting the duration of treatment or the number of admissions in inpatient psychiatric facilities, the indicator is suited to separate clients with and without recent experience with psychiatric inpatient care.

\footnotetext{
${ }^{2}$ In each of these cases "someone" refers to the client.
} 
Of the respondents, $71.7 \%$ had had no inpatient care during the previous year. Experience with mental health treatment seems to be important, because persons with experience are more credible role models for their peers and, hence, more effective support providers (Solomon, 2004), or because experience with inpatient treatment isolates individuals (Nelson et al., 1992).

We measured mental health status using the mean of all the items - the Global Severity Index (GSI) - of the Brief Symptom Checklist (Derogatis, 1993). The GSI is a shorter, 53-item version of the Symptom Checklist, with a reliability score of .97. Previous research has found that people who experience higher levels of stress receive more support (Lu \& Argyle, 1992) and that reciprocity may occur more easily in persons who are relatively asymptomatic (Cohen \& Sokolovsky, 1978; Nelson et al., 1992).

Finally, we included age, gender, and education as control variables. We coded participants' educational level on a 6-point scale ranging from 1 (primary grade level) to 6 (college degree).

\section{Service-Level Control Variables}

We added organizational size as an organizational-level control variable. To measure organizational size, one can choose among the number of staff, the number of clients, or the staff-to-client ratio. The latter is considered a less reliable indicator of organizational size (Martin \& Segal, 1977). Both of the other indicators are used widely to measure the size of human service organizations (Holland, 1973; Martin \& Segal, 1977). To preserve parsimony and because the number of clients has more face value for peer-group processes, we used only the number of clients as a control variable.

\section{Data Analysis}

Because the data set is hierarchically structured, and as clients are clustered within organizations, simple variance components multilevel regression models with clients (first level) nested within service organizations (second level) were fitted to the data. The software package used for this analysis was the hierarchical linear model (HLM; Bryk \& Raudenbush, 1992). We estimated three models using restricted maximum likelihood estimation.

The first estimated model is a null model resulting from an analysis without explanatory variables. This unrestricted model allows us to determine the amount of variation in self-esteem and self-efficacy situated at the organizational level by dividing total variance into between-organization and within-organization variation. Estimations show that, with variance 
components of .07 and $.04,11.5 \%$ of the variation in self-esteem ${ }^{3}$ and $8.7 \%$ of the variation in self-efficacy ${ }^{4}$ (Bryk \& Raudenbush, 1992) exist at the organizational level.

The results of the next steps of the analysis are summarized in Table 1. First, a model (Model 1) was tested containing the social-support measures and all organization-level and client-level control variables. Next, the other outcome indicator was added to estimate the direct effects of the independent variables on either self-esteem or self-efficacy. The client-level and organization-level variables were group mean centered and grand mean centered, respectively, to facilitate the interpretation of the variables and to diminish potential problems of multicollinearity (Kreft \& De Leeuw, 1998).

Results

\section{Bivariate Analyses}

The total amount of support provided equals a mean of 2.71 , while the total amount of support received equals a mean of 2.41, a difference that is highly significant (see Table 2 ), $t(627)=9.73, p<.001$. The scores show that, from the perspective of the clients, the total amount of peer support provided was higher than the amount of peer support received. Item mean scores are presented in Table 2.

The difference between providing and receiving support was small with regard to engaging in a "cozy or warm conversation." The most pronounced gap between receiving and providing support was linked to having confidence in one another. Using self-report data, we are unable to discern whether these findings are biased as a result of respondents overstating their willingness to provide support or understating their dependence on the support of others, in accordance with the norm of reciprocity. Other research has shown that most people view themselves as support donors, rather than recipients $(\mathrm{Lu} \&$ Argyle, 1992; Maton, 1987; Uehara, 1995).

A correlation of $.58(p<.001$; see Table 3$)$ between the clients' scores on total support provided and total support received makes clear that both support transactions are not independent: Support providers are also more willing to seek support from others and vice-versa. Correlations between .51 and .68 have been found in several studies of the general population (Brown et al., 2003; Liang et al., 2001; Schwartz et al., 2003) and studies of seriously mental ill persons (Horwitz, Reinhard, \& Howell-White, 1996; Nelson et al.,

\footnotetext{
${ }^{3} .07 /(.07+.54)=11.5 \%$

${ }^{4} .04 /(.04+.42)=8.7 \%$
} 
448 BRACKE ET AL.

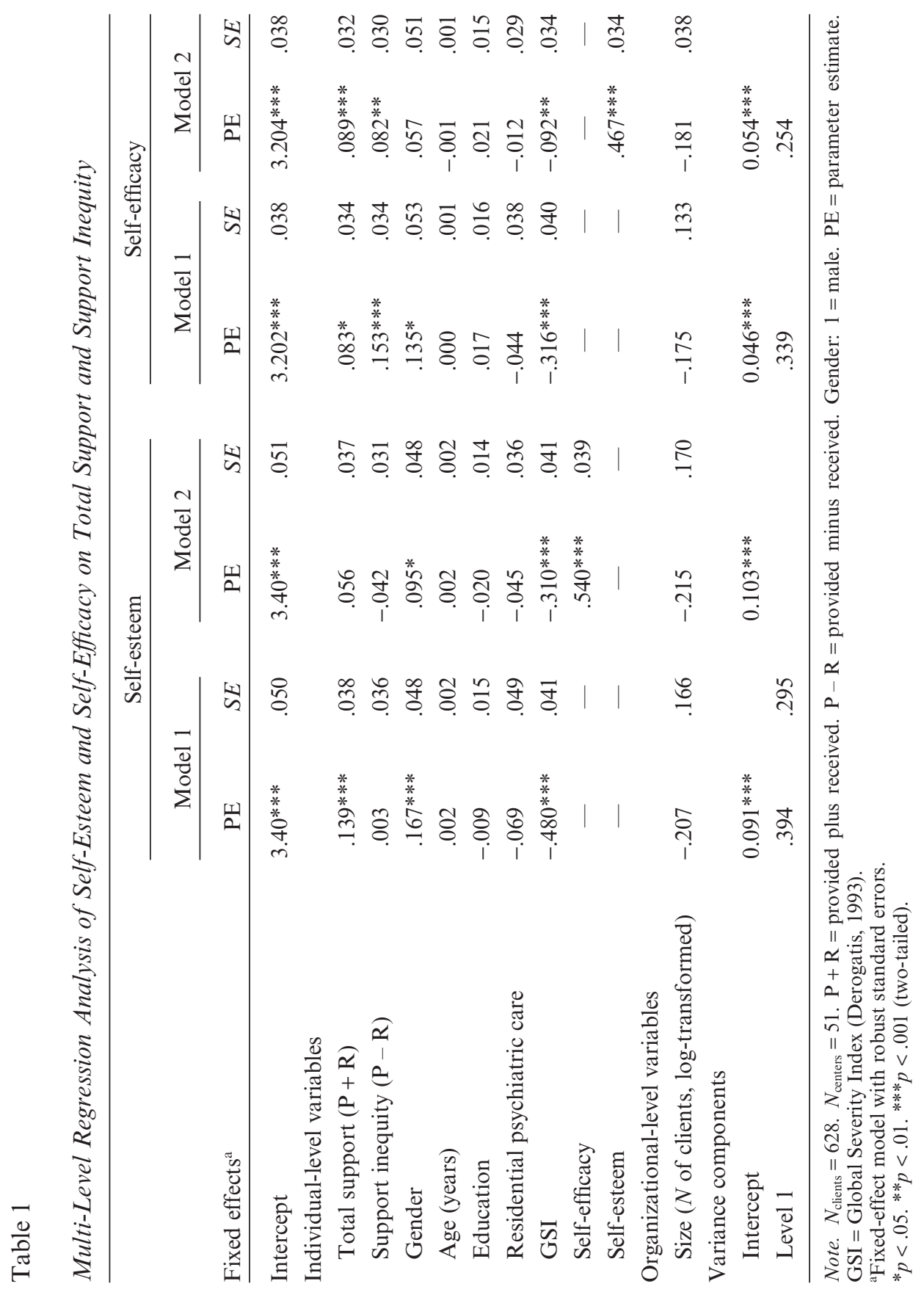


Table 2

Descriptive Statistics on Provided and Received Peer Support

Item wording (support provided): How many times has it happened that... Provided Received Student's $t \quad p$

\begin{tabular}{lllll}
$\begin{array}{l}\text { A visitor asks your help for a } \\
\text { job/household chore? }\end{array}$ & 2.46 & 2.12 & 6.92 & .000 \\
$\begin{array}{l}\text { A visitor stops by for a } \\
\quad \text { cozy/warm conversation? }\end{array}$ & 2.97 & 2.85 & 2.72 & .007 \\
$\begin{array}{l}\text { A visitor contacts you to talk } \\
\quad \begin{array}{l}\text { about his/her problems? } \\
\quad\end{array}\end{array}$ & 2.50 & 2.17 & 6.54 & .000 \\
$\begin{array}{l}\text { A visitor comes to you } \\
\text { because she/he has 100\% } \\
\quad \begin{array}{l}\text { confidence in you? } \\
\text { Overall } M\end{array}\end{array}$ & 2.80 & 2.37 & 8.64 & .000 \\
\hline
\end{tabular}

Note. $N=628$. Visitor $=$ client.

1992). Correspondence between these correlations and the correlation found in the present study augments the validity of the measures used. More importantly, the strength of the association makes clear that an important part of the generalized support exchange is balanced. Nevertheless, the association allows for a great deal of variation around the mean. Furthermore, support inequity is experienced both by isolated and integrated individuals.

Descriptive statistics (Table 3) show that although men's and women's peer networks were characterized by equal amounts of support, men were less eager to perceive themselves as support providers $(r=-.10, p<.01)$. Furthermore, the peer networks of individuals with a recent history of residential psychiatric care were less supportive $(r=-.08, p<.05)$, while present mental health status was not linked to the supportive character of the peer network.

Both self-esteem and self-efficacy were linked to the amount of support received and the amount of support provided. Nevertheless, some important differences can be observed: (a) Self-esteem was associated only with the total amount of peer support $(r=.14, p<.001)$, suggesting that balanced support is more important than overbenefiting or underbenefiting from peer-support transactions; and (b) self-efficacy was linked to both total support $(r=.18$, $p<.001)$ and support inequity $(r=.13, p<.001)$, pointing to the additional 


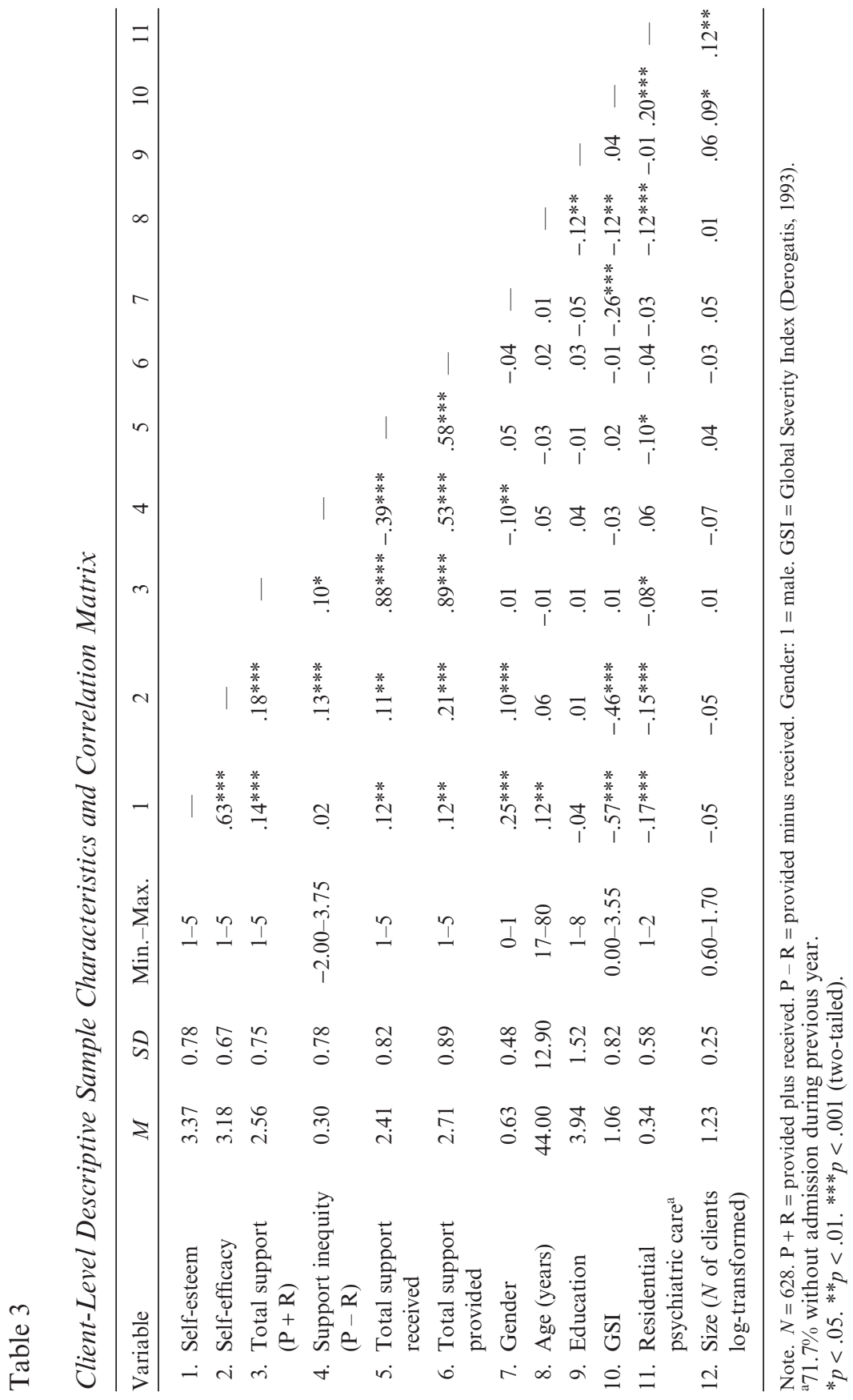


importance of excess support providing for feelings of competence and control.

\section{Multivariate Analyses}

Table 1 summarizes the results of four multilevel analyses. With regard to our main hypotheses, we note several interesting findings. First, as shown in Model 1, self-esteem was strongly influenced by the total amount of perceived peer support $(B=.139, p<.001)$ and not by overbenefiting or underbenefiting from peer-support relations, indicating that balanced peer support augments feelings of self-worth. Because the association is controlled for the mental health status of the clients among others, the finding is rather robust. Adding self-efficacy to the equation (see Model 2) totally removes the aforementioned effect, showing that most of the direct effects of peer support on the self-concept concern feelings of competence.

Second, the two columns at the right-hand side of Table 1 confirm this conclusion. Feelings of self-efficacy are influenced both by total amount of support $(B=.083, p<.05)$ and by support inequity $(B=.153, p<.001)$, suggesting that clients with low levels of balanced support and clients with an excess of received support over provided support have low levels of selfefficacy. Adding feelings of self-esteem to the equation does not alter this conclusion, although the effect of the support inequity is halved.

It is important to note that the aforementioned direct effects of both dimensions of peer support on self-esteem and on self-efficacy are controlled for the mental health status of the clients. Hence, spurious effects caused by the distorted perception of both the amount of support and inequity in support by clients in need of support are controlled for, at least partially.

To finalize the analyses, some interaction effects of both peer-support indicators with client-level and service-level variables were reviewed. The results show that support inequity was especially detrimental to the self-esteem of older clients (support inequity: $B=-.27, S E=.10, p=.005$; Support Inequity $\times$ Age: $B=-.006, S E=.002, p=.014)$. Other significant interaction effects were absent, although some interesting differences between social categories emerged. For instance, direct effects of support on the self-esteem of men were absent, while the self-esteem of women was strongly influenced both by the total amount of support $(B=.08, S E=.035$, $p=.023)$ and support inequity $(B=-.08, S E=.035, p=.023)$. More in-depth analyses indicate clearly that, among women, self-esteem is a function of the amount of support received ( $B=.12, S E=.041, p=.003)$, while providing support is irrelevant. Providing support, in turn, had stronger effects on self-efficacy in men $(B=.16, S E=.05, p=.001)$ than in women $(B=.12$, $S E=.04, p=.001)$. 


\section{Discussion}

Before discussing the findings further, we wish to list briefly some of the shortcomings and merits of the present study in order to avoid any misinterpretation of the data. First, because a cross-sectional design was used, causality is difficult to demonstrate. No doubt, part of the reported associations between the perception of a lack of peer support and low self-esteem, for instance, follows from clients with an injured self-image having a more pessimistic view of the peer-support network surrounding them. We tried to control for perception bias by taking into account the clients' present mental health status. Furthermore, the effects of balance of support on self-efficacy were controlled for clients' level of self-esteem and vice-versa. As an effect, the reported associations between both dimensions of peer support and both dimensions of the self-concept are very conservative estimates.

Second, we were not able to use well-established scales with known psychometric properties to measure the balance of support and support inequity. Nevertheless, we went further than most studies by using scales comprised of more than one item and by using independent indicators of both provided and received peer support to derive information on the balance of support and support inequity. These indicators showed good reliability, and satisfying face and predictive validity.

Third, both dimensions of peer support were measured using clients' self-reports. Consequently, perceived peer support was measured and observational data are needed to confirm the present findings. On the other hand, we think that clients are the most reliable source of information on their contacts with peers. Their perspective cannot be substituted with the perspective of a therapist or a scientist. Additional information from the other clients nonetheless could certainly improve the quality of the information on the peer-support networks. In future research, the whole peer network could be mapped, instead of the present ego-centered networks, using the combined information of all peer-group members in a social network design.

Finally, one of the main merits of the present study is the fact that information was gathered in naturally occurring peer-support networks of persons with severe mental illness in more than 50 different locations, which, to our knowledge is unique. The results of the study are not confined to self-help or mutual-help groups or to settings explicitly designed to encourage peer-group support.

There are three important findings that arise from this investigation. First, the importance of the peer group for the subjective well-being of people with chronic mental health problems is again reaffirmed. Of course, being a replication, this finding is not new. It merely underscores the importance of peers in the recovery process of individuals with mental health problems. 
Second, we have shown that the merits of support emerge when clients had at least their total, ego-centered, peer-support networks in balance or functioned as excess peer-support providers. Hence, support was found for self-esteem enhancement theory and social capital theory, as well as for equity theory, the norm of reciprocity, and the bidirectional hypothesis. Subjective well-being was linked with balanced peer support or net peersupport provision. This finding replicates the results of others (IngersollDayton \& Antonucci, 1988; Israel \& Antonucci, 1987; Jung, 1990, 1997; Liang et al., 2001; Lu, 1997; Lu \& Argyle, 1992; Maton, 1987, 1988; Roberts et al., 1999; Schwartz et al., 2003) albeit in naturally occurring peer-support groups of persons with chronic mental ill health. In addition, they demonstrate that peer-support experts spontaneously come to the forefront, as the results of role-differentiation processes in small groups. The consequences of this finding for the organization of mental health services are apparent. Services must nurture peer-support groups not only because they form a welcome resource clients can turn to in a time of need or a reference group for the interpretation and redefinition of their experiences, but more crucially because these groups provide opportunities to support others and hence to enhance feelings of self-worth and feelings of competence.

Third, two related pathways from support to well-being were identified: Support balance leads to enhanced feelings of self-esteem and self-efficacy; in addition, feelings of self-efficacy are further augmented by being a net provider of support. Both indicators of well-being are important to evaluate the effects of peer support. They concur with communion and agency as two important indicators of subjective well-being (Helgeson, 1994). The question, of course, is how other important outcome indicators of client well-being (e.g., client satisfaction with services) relate to the balance of support and support inequity. Satisfaction with services is an important evaluation criterion, and it is important to know which dimension of peer support - total amount of support or amount of support inequity - is related to satisfaction with services. If satisfaction is partially related to expectations, and clients expect services to provide them with a supportive environment, it could well be that being able to support peers enhances feelings of competence, but diminishes satisfaction with services.

We see additional avenues for further research along several lines. First, we have already noted the importance of longitudinal data to separate social causation from social selection processes. Longitudinal data are vital for another reason, too: They would allow us to introduce a much needed life-course perspective in the study of the relationship between peer-group processes and subjective well-being. A cynical interpretation of the finding of an ameliorating effect of being a support provider states that being a net support provider is only possible if other group members are net support 
receivers. In other words, some persons reap the benefits of providing support because others bear the harmful consequences of being dependent on the support of others. Longitudinal research could help to refute this kind of zero-sum game reasoning by showing that, at some early stage of the recovery process, clients are more in need of support and, hence, have more to gain than to lose - in terms of dependence - from support reception, while later they could start functioning as natural peer-support experts and start enjoying the merits of being able to share their experiences with others. Future research could show how overt and covert hierarchies (Mead, Hilton, \& Curtis, 2001) in peer groups mold the balance of support and form the social context in which clients develop social skills through the various stages of integration in the peer group.

Second, we measured only the overall balance of support in the total, ego-centered, peer-support network. As a result, we are not able to separate dyadic from more general support exchange. Other research has stressed the importance of generalized social exchange (Jung, 1997; Takahashi, 2000), so we assume that in peer-support networks, most of the support exchange is generalized. Nevertheless, it is likely that clients differ in the extent to which they depend on and invest in both forms of support exchange. For instance, it is well known that the social networks of women and men differ (Ridgeway \& Smith-Lovin, 1999) and that close relations are more important in the social networks of women. As a consequence, in order to evaluate the genderspecific impact of peer support on subjective well-being, designs allowing for the separation of dyadic support reciprocity from more general support exchange would be welcome.

Peer-support groups for women and men not only differ in their social structure, but also in their mental-health consequences. We found that the amount of support received has an important impact on the self-esteem of women, while the self-efficacy of men was more strongly influenced by the amount of support provided. This observation underscores the genderdifferential impact of support on the self-concept: For women, to a certain extent, peer support signifies connectedness or communion; while for men, it signifies competence or agency (Helgeson, 1994).

Finally, our results show that peer groups with a preponderance of members who are net providers of support optimize the recovery process of all, in terms of self-esteem and self-efficacy. These peer groups are characterized by a high amount of social capital and function as an important coping resource for all members. It would be interesting to know the organizational prerequisites for the development of these kinds of peer groups. Our results show that the size of the organization, measured as number of clients, has no effect. Of course, more in-depth analyses are needed using various indicators of size and other organizational features, such as client-to-personnel ratios, 
to explore more fully the link between peer-group formation and organizational structure of mental health services. Levin and Brekke's (1993) conclusion that research is needed on the characteristics of the social context influencing clients' integration in peer-based networks obviously still holds.

\section{References}

Anthony, W., Cohen, M., \& Farkas, M. (1990). Psychiatric rehabilitation. Boston: Center for Psychiatric Rehabilitation.

Antonucci, T. C., \& Jackson, J. S. (1990). The role of reciprocity in social support. In B. P. Sarason, I. G. Sarason, \& G. R. Pierce (Eds.), Social support: An interactional view (pp. 129-149). New York: John Wiley \& Sons.

Armstrong, M. L., \& Korba, A. M. (1995). Of mutual benefit: The reciprocal relationship between consumer volunteers and the clients they serve. Psychiatric Rehabilitation Journal, 19, 45-49.

Arns, P. G., \& Linney, J. A. (1993). Work, self, and life satisfaction for persons with severe and persistent mental disorders. Psychosocial Rehabilitation Journal, 17, 63-79.

Bandura, A. (1997). Self-efficacy: The exercise of control. New York: Freeman.

Barrera, M. (1986). Distinctions between social support concepts, measures, and models. American Journal of Community Psychology, 14, 413-445.

Batson, C. D. (1998). Altruism and prosocial behavior. In D. T. Gilbert, S. T. Fiske, \& G. Lindzey (Eds.), The handbook of social psychology (pp. 282316). New York: McGraw-Hill.

Bosscher, R. J., \& Smit, J. H. (1998). Confirmatory factor analysis of the General Self-Efficacy Scale. Behaviour Research and Therapy, 36, 339-343.

Bourdieu, P. (1984). The forms of capital. In J. G. Richardson (Ed.), Handbook of theory and research for the sociology of education (pp. 241-258). New York: Greenwood.

Brown, S. L., Nesse, R. M., Vinokur, A. D., \& Smith, D. M. (2003). Providing social support may be more beneficial than receiving it: Results from a prospective study of mortality. Psychological Science, 14, 320-327.

Brutsaert, H. (1993). School, gezin en welbevinden. Zesdeklassers en hun sociale omgeving [School, family, and well-being. Third graders and their social context]. Leuven, Belgium: Garant.

Bruynooghe, K., Bracke, P., \& Verhaeghe, M. (2003). De psychometrische eigenschappen van een Nederlandstalige versie van de Rosenbergzelfwaarderingsschaal [The psychometric properties of a Dutch version of the Rosenberg Self-Esteem Scale]. Diagnostiek-Wijzer, 6, 136-146. 
Bryk, A. S., \& Raudenbush, S. W. (1992). Hierarchical linear models: Applications and data analysis methods ( $1^{\text {st }}$ ed.). Newbury Park, CA: Sage.

Cohen, C. I., \& Sokolovsky, J. (1978). Schizophrenia and social networks: Ex-patients in inner city. Schizophrenia Bulletin, 4, 546-560.

Cohen, S., \& Wills, T. A. (1985). Stress, social support, and the buffering hypothesis. Psychological Bulletin, 98, 310-357.

Coleman, J. (1990). Foundations of social theory. Cambridge, MA: Harvard University Press.

Coyne, J. C., Ellard, J. H., \& Smith, D. A. (1990). Social support, interdependence, and the dilemmas of helping. In B. P. Sarason, I. G. Sarason, \& G. R. Pierce (Eds.), Social support: An interactional view (pp. 129-149). New York: John Wiley \& Sons.

Davidson, L., Chinman, M., Kloos, B., Weingarten, R., Stayner, D., \& Tebes, J. K. (1999). Peer support among individuals with severe mental illness: A review of the evidence. Clinical Psychology: Science and Practice, 6, 165-187.

Derogatis, L. R. (1993). BSI: Brief Symptom Inventory. Administration, scoring, and procedures manual. Minneapolis, MN: NCS Assessments.

Ekeh, P. P. (1974). Social exchange theory: Two traditions. Cambridge, MA: Harvard University Press.

England, P., \& Folbre, N. (1999). The cost of caring. Annals of the American Academy of Political and Social Science, 561, 39-51.

Fisher, J. D., Nadler, A., \& Whitcher-Alagna, S. (1982). Recipient reactions to aid. Psychological Bulletin, 91, 27-54.

Gecas, V. (1982). The self-concept. Annual Review of Sociology, 8, 1-33.

Gecas, V. (1989). The social psychology of self-efficacy. Annual Review of Sociology, 15, 291-316.

Goering, P., Durbin, J., Foster, R., Boyles, S., Babiak, T., \& Lancee, B. (1992). Social networks of residents in supportive housing. Community Mental Health Journal, 28, 199-214.

Gouldner, A. W. (1960). The norm of reciprocity: A preliminary statement. American Sociological Review, 25, 161-178.

Helgeson, V. S. (1994). Relation of agency and communion to well-being: Evidence and potential explanations. Psychological Bulletin, 116, 412428.

Hogan, B. E., Linden, W., \& Najarian, B. (2002). Social support interventions: Do they work? Clinical Psychology Review, 22, 381-440.

Holland, T. P. (1973). Organizational structure and institutional care. Journal of Health and Social Behavior, 14, 241-251.

Horwitz, A. V., Reinhard, S. C., \& Howell-White, S. (1996). Caregiving as reciprocal exchange in families with seriously mentally ill members. Journal of Health and Social Behavior, 37, 149-162. 
Hunt, C. K. (2003). Concepts in caregiver research. Journal of Nursing Scholarship, 35, 27-32.

Ingersoll-Dayton, B., \& Antonucci, T. C. (1988). Reciprocal and nonreciprocal social support: Contrasting sides of intimate relationships. Journal of Gerontology, 43, S65-S73.

Israel, B. A., \& Antonucci, T. C. (1987). Social network characteristics and psychological well-being: A replication and extension. Health Education Quarterly, 14, 461-481.

Jung, J. (1990). The role of reciprocity in social support. Basic and Applied Social Psychology, 11, 243-253.

Jung, J. (1997). Balance and source of social support in relation to well-being. Journal of General Psychology, 124, 77-90.

Kessler, R. C., Price, R. H., \& Wortman, C. B. (1985). Social factors in psychopathology: Stress, social support, and coping processes. Annual Review of Psychology, 36, 531-572.

Kreft, I., \& De Leeuw, J. (1998). Introducing multilevel modeling. London: Sage.

Levin, S., \& Brekke, J. S. (1993). Factors related to integrating persons with chronic mental illness into a peer social milieu. Community Mental Health Journal, 29, 25-34.

Liang, J., Krause, N. M., \& Bennett, J. M. (2001). Social exchange and well-being: Is giving better than receiving? Psychology and Aging, 16, 511-523.

Lin, N., \& Peek, M. K. (1999). Social networks and mental health. In A. V. Horwitz \& T. L. Scheid (Eds.), A handbook for the study of mental health: Social contexts, theories, and systems (pp. 241-258). New York: Cambridge University Press.

Lu, L. (1997). Social support, reciprocity, and well-being. Journal of Social Psychology, 137, 618-628.

Lu, L., \& Argyle, M. (1992). Receiving and giving support: Effects on relationships and well-being. Counselling Psychology Quarterly, 5, 123-133.

Macinko, J., \& Starfield, B. (2001). The utility of social capital in research on health determinants. Milbank Quarterly, 79, 387-427.

Martin, P. Y., \& Segal, B. (1977). Bureaucracy, size, and staff expectations for client independence in halfway houses. Journal of Health and Social Behavior, 18, 376-390.

Maton, K. I. (1987). Patterns and psychological correlates of material support within a religious setting: The bidirectional support hypothesis. American Journal of Community Psychology, 15, 185-207.

Maton, K. I. (1988). Social support, organizational characteristics, psychological well-being, and group appraisal in three self-help group populations. American Journal of Community Psychology, 16, 53-77. 
Mead, S., Hilton, D., \& Curtis, L. (2001). Peer support: A theoretical perspective. Psychiatric Rehabilitation Journal, 25, 134-141.

Mowbray, C. T., \& Moxley, D. P. (1998). Consumers as mental health providers: First-person account of benefits and limitations. Journal of Behavioral Health Services and Research, 25, 397-411.

Nelson, G., Hall, G. B., Squire, D., \& Walsh-Bowers, R. T. (1992). Social network transactions of psychiatric patients. Social Science and Medicine, $34,433-445$.

Pearlin, L. I., Mullan, J. T., Semple, S. J., \& Skaff, M. M. (1990). Caregiving and the stress process: An overview of concepts and their measures. Gerontologist, 30, 583-594.

Pickett, S. A., Cook, J. A., \& Razzano, L. (1999). Psychiatric rehabilitation services and outcomes: An overview. In A. V. Horwitz \& T. L. Scheid (Eds.), A handbook for the study of mental health (pp. 484-492). New York: Cambridge University Press.

Ridgeway, C. L., \& Smith-Lovin, L. (1999). The gender system and interaction. Annual Review of Sociology, 25, 191-216.

Riessman, F. (1965). The "helper-therapy" principle. Social Work, 10, 3732.

Roberts, L. J., Salem, D., Rappaport, J., Toro, P. A., Luke, D. A., \& Seidman, E. (1999). Giving and receiving help: Interpersonal transactions in mutual-help meetings and psychosocial adjustment of members. American Journal of Community Psychology, 27, 841-868.

Rose, R. (2000). How much does social capital add to individual health? A survey study of Russians. Social Science and Medicine, 51, 1421-1435.

Rosenberg, M. (1965). Society and the adolescent self-image. Princeton, NJ: Princeton University Press.

Rosenfield, S., \& Wenzel, S. (1997). Social networks and chronic mental illness: A test of four perspectives. Social Problems, 44, 200-216.

Salem, D. A., Reischl, T. M., Gallacher, F., \& Randall, K. W. (2000). The role of referent and expert power in mutual help. American Journal of Community Psychology, 28, 303-324.

Salzer, M. S., \& Shear, S. L. (2002). Identifying consumer-provider benefits in evaluations of consumer-delivered services. Psychiatric Rehabilitation Journal, 25, 281-288.

Sarason, I. G., Pierce, G. R., \& Sarason, B. R. (1994). General and specific perceptions of social support. In W. R. Avison \& I. H. Gotlib (Eds.), Stress and mental health: Contemporary issues and prospects for the future (pp. 151-177). New York: Plenum.

Schwartz, C., Meisenhelder, J. B., Ma, Y. S., \& Reed, C. (2003). Altruistic social interest behaviors are associated with better mental health. Psychosomatic Medicine, 65, 778-785. 
Schwartz, C. E., \& Sendor, R. M. (1999). Helping others helps oneself: Response shift effects in peer support. Social Science and Medicine, 48, $1563-1575$.

Segal, S. P., Silverman, C., \& Temkin, T. (1995). Measuring empowerment in client-run self-help agencies. Community Mental Health Journal, 31, 215227.

Sherer, M., Maddux, J. E., Mercandante, B., Prentice-Dunn, S., Jacobs, B., \& Rogers, R. W. (1982). The Self-Efficacy Scale: Construction and validation. Psychological Reports, 51, 663-671.

Skovholt, T. M. (1974). Client as helper: Means to promote psychological growth. Counseling Psychologist, 4, 58-64.

Solomon, P. (2004). Peer support/peer provided services underlying processes, benefits, and critical ingredients. Psychiatric Rehabilitation Journal, 27, 392-401.

Takahashi, N. (2000). The emergence of generalized exchange. American Journal of Sociology, 105, 1105-1134.

Taylor, J., \& Turner, R. J. (2001). A longitudinal study of the role and significance of mattering to others for depressive symptoms. Journal of Health and Social Behavior, 42, 310-325.

Thoits, P. A. (1995). Stress, coping, and social support processes: Where are we-what next. Journal of Health and Social Behavior, 35, 53-79.

Thoits, P. A., \& Hewitt, L. N. (2001). Volunteer work and well-being. Journal of Health and Social Behavior, 42, 115-131.

Turner, R. J., \& Turner, J. B. (1999). Social integration and support. In C. S. Aneshensel (Ed.), Handbook of the sociology of mental health (pp. 301319). New York: Kluwer Academic/Plenum.

Uehara, E. S. (1995). Reciprocity reconsidered: Gouldner's moral norm of reciprocity and social support. Journal of Social and Personal Relationships, 12, 483-502.

Walster, E., Walster, G. W., \& Berscheid, E. (1978). Equity: Theory and research. Boston: Allyn \& Bacon.

Wilken, J. P., \& den Hollander, D. (1999). Psychosociale rehabilitatie. Een integrale benadering [Psychosocial rehabilitation. An integral approach]. Utrecht, The Netherlands: Uitgeverij SWP.

Williams, H. A. (1995). There are no free gifts: Social support and the need for reciprocity. Human Organization, 54, 401-409.

Wilson, M. E., Flanagan, S., \& Rynders, C. (1999). The FRIENDS Program: A peer support group model for individuals with a psychiatric disability. Psychiatric Rehabilitation Journal, 22, 239-247.

Yamagishi, T., \& Cook, K. S. (1993). Generalized exchange and social dilemmas. Social Psychology Quarterly, 56, 235-248. 